\title{
Improvement of Analytical Methods for the Determination of Polyphenolic Bioactive Compounds in Berry Fruits
}

\author{
Marisa Carmela Caruso, ${ }^{1}$ Fernanda Galgano, ${ }^{1}$ Maria Pecora, ${ }^{1}$ Roberta Tolve, ${ }^{1}$ \\ Maria Verrastro, ${ }^{1}$ and Fabio Favati $^{2}$ \\ ${ }^{1}$ School of Agriculture, Forestry, Food and Environmental Science, University of Basilicata, Viale dell'Ateneo Lucano 10, \\ 85100 Potenza, Italy \\ ${ }^{2}$ Department of Biotechnology, University of Verona, Ca' Vignal 1, Strada Le Grazie 15, 37134 Verona, Italy
}

Correspondence should be addressed to Marisa Carmela Caruso; marisa.caruso@unibas.it

Received 24 January 2015; Revised 27 May 2015; Accepted 4 June 2015

Academic Editor: Ghada M. Hadad

Copyright ( 2015 Marisa Carmela Caruso et al. This is an open access article distributed under the Creative Commons Attribution License, which permits unrestricted use, distribution, and reproduction in any medium, provided the original work is properly cited.

Berry fruits contain high levels of different phytochemicals, most of which are phenolic molecules. Fruits of the same cultivar from different locations and different harvest years have different chemical compositions, particularly related to polyphenols. The difference may be due to specific climatic conditions, the type of soil in which the plants grow, and the stresses to which the plants were subjected because these phytochemicals are produced as a defense mechanism through a secondary metabolic process. For this reason, it is important to establish simple and reliable procedure to determine polyphenolic compounds in berry fruits considering the increasing attention on these compounds for different potential uses. In order to choose and to improve the most adequate analytical procedure for the determination of the polyphenolic substances in berry fruits, different methods were applied and compared on samples of elderberry and blackberry.

\section{Introduction}

The importance of food consumption in relation to human health has increased chemist, nutritionist, and consumer attention in nutraceutical components present in foods. Berry fruits are rich in nutrients and in phytochemicals that can prevent various diseases and disorders. Most of the health benefits due to berry fruits are related to various polyphenols, which are compounds with antioxidant property and antitumor potential. They can counteract oxidative stress, exert beneficial effects on blood pressure, increase the activity of antioxidant enzymes in the blood plasma, and are also involved in glycaemia reduction and immune system stimulation [1,2]. Moreover, recently studies have demonstrated that anthocyanins and proanthocyanidins present in juice obtained from blackberry (Rubus fruticosus) have antimicrobial activity against different foodborne pathogens, whereas they significantly stimulate the growth of Lactobacillus species. This finding opens the possibility of new probiotic therapies to improve the gut health and an alternative to antibiotic treatments [3, 4]. Accumulating evidences suggest that genotype has a profound influence on concentrations of bioactive compounds in berries $[5,6]$. Within the same fruit type, the growing season, variety, environmental and climatic conditions, plant disease, soil type, geographic location, and even maturity and postharvest handling procedures seem to influence the concentration of phenolic compounds [7-9]. Considering the relevance of the berry fruits in the human diet and their potential use as colouring agent, functional ingredients, and dietary supplement $[10,11]$, it is very important to have standardized methods to identify and quantify their polyphenolic substances, taking into account the great variability present between different species, cultivars, and wild genotype. Polyphenols comprise a wide variety of compounds, divided into several classes, like hydroxybenzoic acids, hydroxycinnamic acids, anthocyanins, proanthocyanidins, flavonols, flavones, flavanols, flavanones, isoflavones, stilbenes, and lignans $[12,13]$. The methods employed for total 
polyphenols determination were generally based on FolinCiocalteau's phenol reagent and spectrophotometric determination $[9,14]$. Simple spectrophotometric methods are also available for total anthocyanin and total flavonoid determination. In particular, total anthocyanins were determined using a $\mathrm{pH}$ differential method, based on their transformation to red-coloured flavylium cation under acidic conditions determination $[9,15]$, whereas the total flavonoid content can be determined using a colorimetric method based on the complexation of the phenolic compounds with $\mathrm{Al}$ (III) [16]. However, it is of great interest to identify and quantify individual phenolics in berry fruits. With this aim, a great number of analytical procedures have been described in literature. Most of them are based on high performance liquid chromatography (HPLC). The chromatographic conditions of the HPLC methods generally include a reversed-phase C18 column, an UV-VIS detector, and a binary solvent system containing acidified water (solvent A) and a polar organic solvent (solvent B) [7, 17-22]. For accurate peak identification, procedures based on LC-MS, HPLC-PDA, and HPLC-ESIMS have also been reported [17, 20, 23]. In order to facilitate the identification of phenolic compounds using the UV-VIS detector, acidic hydrolysis may be carried out before injection of the sample into the HPLC system. In this way, they are determined as aglycones [7, 21, 22]. Also, it is to consider that the steps of extraction and purification of the polyphenols from complex matrices, such as foodstuffs, are of great importance for the outcome of the HPLC analysis [12].

This paper has as its objective the evaluation and comparison of different analytical methods for some polyphenolic compounds determination, in order to optimize the results, in terms of the purity of the sample extract and the recovery of the considered substances. Moreover, in order to improve the chromatographic separation of analytes, some modifications have been made with respect to methods available in literature. The berry fruits considered in this study belonged to Sambucus nigra and Rubus species.

\section{Material and Methods}

2.1. Plant Material. Approximately $1 \mathrm{~kg}$ of fully ripe fruits of wild grown elderberry and blackberry (3 samples of each species) was picked in different areas of Basilicata and Campania regions (Southern Italy), in the period from the last week of July until the first week of September. Additionally, one sample of commercial blackberry (Rubus fruticosus) was considered. Elderberry fruits were harvested with stalks. Before harvesting, plant parts were collected during flowering, and species identification was performed according to Pignatti [24]. Fresh fruits were packed in plastic bags, frozen, and kept at $-20^{\circ} \mathrm{C}$ until analysis.

2.2. Extraction of Phenolic Compounds. Two different protocols were applied.

2.2.1. Methanolic Extraction. The extraction of phenolic compounds was carried out with three subsequent extractions with $15 \mathrm{~mL}$ of methanol/HCl $0.01 \mathrm{~N}(9: 1)$ on $10 \mathrm{~g}$ of homogenized fruits. Seeds and skin are not separated, whereas elderberry stalks were removed. Each time, after acidified methanol addition, the sample was vortexed for $2 \mathrm{~min}$ and then centrifugated at $3500 \mathrm{~g}$ for $10 \mathrm{~min}$ at $10^{\circ} \mathrm{C}$.

\subsubsection{Methanolic Extraction with Ultrasound Treatment.}

Phenolics were extracted according to the method previously described by Veberic et al. [17] with slight modification. Briefly, $1 \mathrm{~g}$ of homogenized berries was extracted with $20 \mathrm{~mL}$ methanol containing $1 \% \mathrm{HCl}$ in an ultrasonic bath for $30 \mathrm{~min}$ at $25^{\circ} \mathrm{C}$. After sonication, the solvent was recovered by centrifugation at $3500 \mathrm{~g}$ for $10 \mathrm{~min}$ at $10^{\circ} \mathrm{C}$.

The extracts were stored at $-20^{\circ} \mathrm{C}$ prior to analysis.

2.3. Fractionation of Phenolics. Twenty milliliters of the methanolic extract above described (see Section 2.2.1) was subjected to a series of liquid-liquid extractions in order to remove interfering substances and to fractionate the phenolic components. Precisely, the extract was washed with n-hexane and chloroform. Polyphenolics were then fractionated by means of three subsequent extractions with $7 \mathrm{~mL}$ of ethyl acetate in order to separate anthocyanins (residual fraction) from other phenolic compounds (ethyl acetate soluble fraction). Both fractions were analyzed for anthocyanins and flavonols content by HPLC.

2.4. Hydrolysis of Flavonols. Flavonols were detected as aglycones after acidic hydrolysis, performed according to the method applied by Ageel et al. [25] on Ginko biloba leaf extract, but reducing the volume of the reaction mixture. Precisely, $100 \mu \mathrm{L}$ of methanolic extract were diluted with $200 \mu \mathrm{L}$ of water and $50 \mu \mathrm{L}$ of $\mathrm{HCl} 12 \mathrm{M}$ (final concentration of $1.7 \mathrm{M} \mathrm{HCl}$ ) and vortexed for $2 \mathrm{~min}$. Tubes were then placed in a boiling water bath for $30 \mathrm{~min}$ and allowed to react. Once the hydrolysis was completed, the sample was cooled under running water and $150 \mu \mathrm{L}$ of $\mathrm{MeOH}$ was added, in order to obtain a final volume of $500 \mu \mathrm{L}$ of the hydrolyzate.

\subsection{Ellagic Acid Extraction and Hydrolysis. Two different} protocols were applied.

2.5.1. Simultaneous Methanolic Extraction and Hydrolysis. A 5-g portion of homogenized fruit was weighed into a rotavapor flask and $5 \mathrm{~mL}$ of water containing $80 \mathrm{mg}$ of ascorbic acid, $20 \mathrm{~mL}$ of methanol, and $5 \mathrm{~mL}$ of concentrated $\mathrm{HCl}$ was added. The mixture was refluxed for $5 \mathrm{~h}$ at $90^{\circ} \mathrm{C}$.

\subsubsection{Hydrolysis of the Methanolic Extract with Ultrasound} Treatment. The methanolic extract described in Section 2.2.2 and hydrolyzed as reported in Section 2.4 was also used for ellagic acid quantification.

2.6. HPLC Analysis. HPLC was performed with a VarianAgilent system, consisting in a ternary pump 9050 series and an UV-Vis detector 9050 series coupled to a STAR 4.5 software for data acquisition and elaboration. A Gemini NX 
TABLE 1: Content of anthocyanins in the traditional and ultrasonic extracts (results from 3 independent replicates).

\begin{tabular}{|c|c|c|c|c|c|}
\hline \multirow[b]{2}{*}{ Sample } & \multirow[b]{2}{*}{ Analyte } & \multicolumn{2}{|c|}{ Methanolic extract } & \multicolumn{2}{|c|}{ Methanolic extract with ultrasound treatment } \\
\hline & & 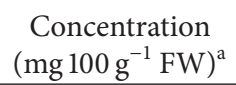 & $\begin{array}{c}\mathrm{RSD} \\
(\%)\end{array}$ & 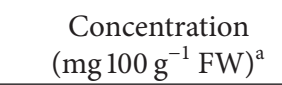 & $\begin{array}{l}\text { RSD } \\
(\%)\end{array}$ \\
\hline \multirow{2}{*}{ S1 (S. nigra) } & Cy-3-glucoside & 201.22 & 8.18 & 209.48 & 13.84 \\
\hline & Cy-3-sambubioside & 271.43 & 12.22 & 285.95 & 6.69 \\
\hline \multirow{2}{*}{ S2 (S. nigra) } & Cy-3-glucoside & 188.21 & 5.34 & 179.76 & 7.94 \\
\hline & Cy-3-sambubioside & 220.46 & 11.22 & 232.74 & 12.08 \\
\hline \multirow{2}{*}{ S3 (S. nigra) } & Cy-3-glucoside & 179.13 & 8.45 & 156.70 & 7.15 \\
\hline & Cy-3-sambubioside & 339.14 & 4.41 & 353.27 & 6.39 \\
\hline \multirow{4}{*}{ M1 (R. ulmifolius) } & Cy-3-glucoside & 33.03 & 3.57 & 36.06 & 5.32 \\
\hline & $\mathrm{A} 1$ & n.d. & - & n.d. & - \\
\hline & A2 & 44.68 & 6.88 & 49.94 & 4.40 \\
\hline & A3 & 45.84 & 5.34 & 42.67 & 4.40 \\
\hline \multirow{4}{*}{ M2 (R. ulmifolius) } & Cy-3-glucoside & 16.98 & 8.22 & 18.82 & 6.00 \\
\hline & $\mathrm{A} 1$ & n.d. & - & n.d. & - \\
\hline & A2 & 29.44 & 2.37 & 27.32 & 6.44 \\
\hline & A3 & 29.88 & 7.87 & 32.52 & 6.12 \\
\hline \multirow{4}{*}{ M3 (R. procerus) } & Cy-3-glucoside & 24.58 & 9.98 & 20.21 & 8.66 \\
\hline & $\mathrm{A} 1$ & 22.84 & 7.84 & 26.96 & 7.04 \\
\hline & $\mathrm{A} 2$ & 29.32 & 4.22 & 26.99 & 5.70 \\
\hline & $\mathrm{A} 3$ & 25.49 & 6.77 & 33.31 & 6.04 \\
\hline \multirow{4}{*}{ M4 (R. fruticosus) } & Cy-3-glucoside & 151.88 & 3.54 & 177.67 & 5.43 \\
\hline & $\mathrm{A} 1$ & 21.84 & 9.22 & 23.07 & 2.90 \\
\hline & $\mathrm{A} 2$ & 28.55 & 7.55 & 26.04 & 4.22 \\
\hline & A3 & 31.18 & 6.49 & 29.96 & 3.44 \\
\hline
\end{tabular}

RSD: relative standard deviation; ${ }^{a}$ mean value; n.d.: not detected.

C18 110 À column, $250 \times 4.6 \mathrm{~mm}$ (Phenomenex), protected by guard column, was the stationary phase.

Anthocyanins and flavonols were separated by gradient elution with $10 \%(\mathrm{v} / \mathrm{v})$ formic acid in water (solvent $\mathrm{A}$ ) and $50: 40: 10(\mathrm{v} / \mathrm{v} / \mathrm{v})$ acetonitrile : water : formic acid (solvent B), according to the gradient program reported by Sójka et al. [26]. The injection volume was $20 \mu \mathrm{L}$ and the column temperature was set at $40^{\circ} \mathrm{C}$. Anthocyanins were detected at $520 \mathrm{~nm}$, while flavonols were detected at $360 \mathrm{~nm}$.

Ellagic acid was quantified separately, using $0.1 \%$ phosphoric acid (solvent A) and 100\% methanol (solvent B), according to the gradient program reported by Jakobek and Seruga [19]. The injection volume was $20 \mu \mathrm{L}$ and the column temperature was $20^{\circ} \mathrm{C}$, whereas detection length was $260 \mathrm{~nm}$.

Prior to injection in HPLC system, samples were filtered through a PTFE $0.45 \mu \mathrm{m}$ pore-size filter. Quantification was performed based on external standards of known concentrations. Anthocyanins were expressed as cyanidin chloride equivalents.

\section{Results and Discussion}

3.1. Anthocyanins and Flavonols Extraction and Quantification. All the three elderberry samples were identified as Sambucus nigra. As regards blackberry samples, two of them, harvested in Basilicata region, belonged to Rubus ulmifolius species whereas the third, harvested in Campania region, belonged to Rubus procerus species. Two different methods were used with the aim of extracting the phenolic substances, one of which by using ultrasound assisted extraction, and the results obtained were reported in Tables 1 and 2. Recently ultrasound assisted extraction has gained particular attention due to low cost equipment, simplicity, higher efficiency with respect to extraction time and solvent consumption requirements, extraction yields, and improved quality of the extracts. Ultrasound-induced cavitation process causes swelling of plant cells and facilitates washing out of solute from disrupted cell walls [22]. Methanol was used in both procedures as solvent of extraction. Acetone or methanol solvents, pure or combined with water or acids (acetic, formic, and hydrochloric), are the most common extracting system used in the phenolic compound analyses, but methanol-based solvent has been shown to be the best for anthocyanin recovery. In some studies it has been reported that the anthocyanin molecules undergo significant structural modifications in aqueous acetone, leading to the formation of pyranoanthocyanins and furoanthocyanidins, a phenomenon that does not occur in acidified methanol $[27,28]$. Our results showed that, under the applied conditions, flavonols were better extracted using ultrasounds (about $20 \%$ of increased recovery), whereas the 
TABLE 2: Content of flavonols in the traditional and ultrasonic extracts (results from 3 independent replicates).

\begin{tabular}{|c|c|c|c|c|c|}
\hline \multirow[b]{2}{*}{ Sample } & \multirow[b]{2}{*}{ Analyte } & \multicolumn{2}{|c|}{ Methanolic extract } & \multicolumn{2}{|c|}{ Methanolic extract with ultrasound treatment } \\
\hline & & $\begin{array}{c}\text { Concentration } \\
\left(\mathrm{mg} 100 \mathrm{~g}^{-1} \mathrm{FW}\right)^{\mathrm{a}}\end{array}$ & $\begin{array}{c}\text { RSD } \\
(\%)\end{array}$ & 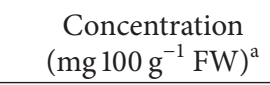 & $\begin{array}{c}\mathrm{RSD} \\
(\%)\end{array}$ \\
\hline \multirow{3}{*}{ S1 (S. nigra) } & Quercetin & 14.77 & 5.76 & 18.98 & 4.12 \\
\hline & Kaempferol & n.d. & - & n.d. & - \\
\hline & Myricetin & n.d. & - & n.d. & - \\
\hline \multirow{3}{*}{ S2 (S. nigra) } & Quercetin & 12.32 & 6.04 & 16.07 & 3.88 \\
\hline & Kaempferol & n.d. & - & n.d. & \\
\hline & Myricetin & n.d. & - & n.d. & \\
\hline \multirow{3}{*}{ S3 (S. nigra) } & Quercetin & 7.12 & 5.43 & 11.88 & 5.16 \\
\hline & Kaempferol & n.d. & - & n.d. & - \\
\hline & Myricetin & n.d. & - & n.d. & - \\
\hline \multirow{3}{*}{ M1 (R. ulmifolius) } & Quercetin & n.d. & - & n.d. & - \\
\hline & Kaempferol & 22.12 & 4.45 & 30.86 & 8.87 \\
\hline & Myricetin & 10.74 & 7.55 & 14.34 & 5.23 \\
\hline \multirow{3}{*}{ M2 (R. ulmifolius) } & Quercetin & n.d. & - & n.d. & - \\
\hline & Kaempferol & 355.62 & 4.12 & 444.86 & 8.12 \\
\hline & Myricetin & 146.42 & 7.71 & 200.25 & 7.16 \\
\hline \multirow{3}{*}{ M3 (R. procerus) } & Quercetin & n.d. & - & n.d. & - \\
\hline & Kaempferol & 18.71 & 3.45 & 23.84 & 11.32 \\
\hline & Myricetin & 3.31 & 2.13 & 4.83 & 5.15 \\
\hline \multirow{3}{*}{ M4 (R. fruticosus) } & Quercetin & n.d. & - & n.d. & - \\
\hline & Kaempferol & 30.16 & 6.76 & 41.56 & 6.77 \\
\hline & Myricetin & 1.12 & 7.72 & 1.56 & 8.15 \\
\hline
\end{tabular}

RSD: relative standard deviation; ${ }^{a}$ mean value; n.d.: not detected.

recovery of anthocyanins with the two different procedures was about the same. However, it can be underlined that the ultrasound assisted procedure involved a lower number of analytical steps, and therefore it is preferable.

In literature, the extraction of flavonols by ethyl acetate from food matrix prior to HPLC analysis has been reported $[19,29]$. In our case, HPLC analysis of the phenolics obtained by liquid-liquid extraction on the primary methanolic extract revealed that there was not a good separation among flavonols (expected in the ethyl acetate fraction) and anthocyanins (expected in the residual aqueous fraction). In fact, both the ethyl acetate and aqueous fraction contained either flavonoids or anthocyanins, even if in different amounts. Therefore, this analytical procedure applied on berry fruits was not satisfactory.

Cyanidin-3-glucoside and cyanidin-3-sambubioside were previously reported as the prevailing anthocyanins in elderberry. In Sicilian elderberry (from Italy) cyanidin-3glucoside was prevailing [30], whereas in our samples and in Austrian elderberry selection cyanidin-3-sambubioside was the major anthocyanin [17]. It is important to note that, in our analytical conditions, the two anthocyanins, even if they had similar retention time, could be sufficiently separated and quantified (Figure 1), whereas in other procedures they coeluted [17]. In blackberry fruits, four anthocyanins were determined (Figure 2), one of which was identified as cyanidin-3-glucoside, whereas the others, reported as A1,

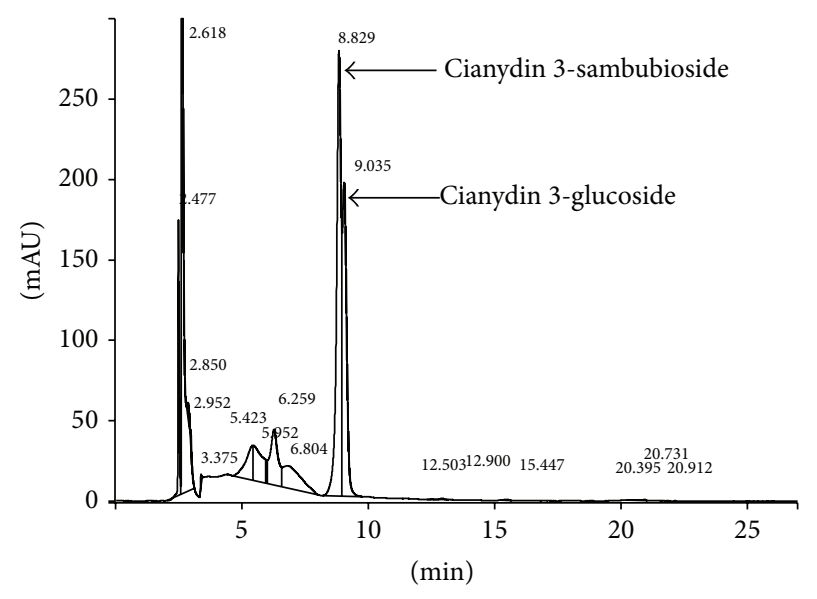

FIGURE 1: Anthocyanins in elderberry methanolic extract.

A2, and A3, were unidentified. Berry fruits of the genus Rubus possess anthocyanins with very complex chemical structure, and prevailing cyaniding-glycosides, sometimes elucidated by means of ESI-MS and NMR techniques $[20,22]$. As regards individual flavonol aglycone contents, in agreement with the literature, elderberry contained only quercetin, whereas in blackberry kaempferol and myricetin were present $[9,14,17]$. 
TABLE 3: Ellagic acid obtained from the traditional and new rapid procedure (results from 3 independent replicates).

\begin{tabular}{|c|c|c|c|c|c|}
\hline \multirow[b]{2}{*}{ Sample } & \multirow[b]{2}{*}{ Analyte } & \multicolumn{2}{|c|}{ Methanolic extract/hydrolysis } & \multicolumn{2}{|c|}{ Methanolic extract with ultrasound treatment/hydrolysis } \\
\hline & & 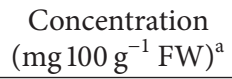 & $\begin{array}{l}\mathrm{RSD} \\
(\%)\end{array}$ & $\begin{array}{c}\text { Concentration } \\
\left(\mathrm{mg} \mathrm{100}^{-1} \mathrm{FW}\right)^{\mathrm{a}}\end{array}$ & $\begin{array}{l}\text { RSD } \\
(\%)\end{array}$ \\
\hline S1 (S. nigra) & Ellagic acid & n.d. & - & n.d. & - \\
\hline S2 (S. nigra) & Ellagic acid & n.d. & - & n.d. & - \\
\hline S3 (S. nigra) & Ellagic acid & n.d. & - & n.d. & - \\
\hline M1 (R. ulmifolius) & Ellagic acid & 81.12 & 7.43 & 119.17 & 6.12 \\
\hline M2 (R. ulmifolius) & Ellagic acid & 144.65 & 10.15 & 200.06 & 4.31 \\
\hline M3 (R. procerus) & Ellagic acid & 50.40 & 7.27 & 77.40 & 3.15 \\
\hline M4 (R. fruticosus) & Ellagic acid & 22.12 & 9.14 & 29.70 & 5.74 \\
\hline
\end{tabular}

RSD: relative standard deviation; ${ }^{a}$ mean value; n.d.: not detected.

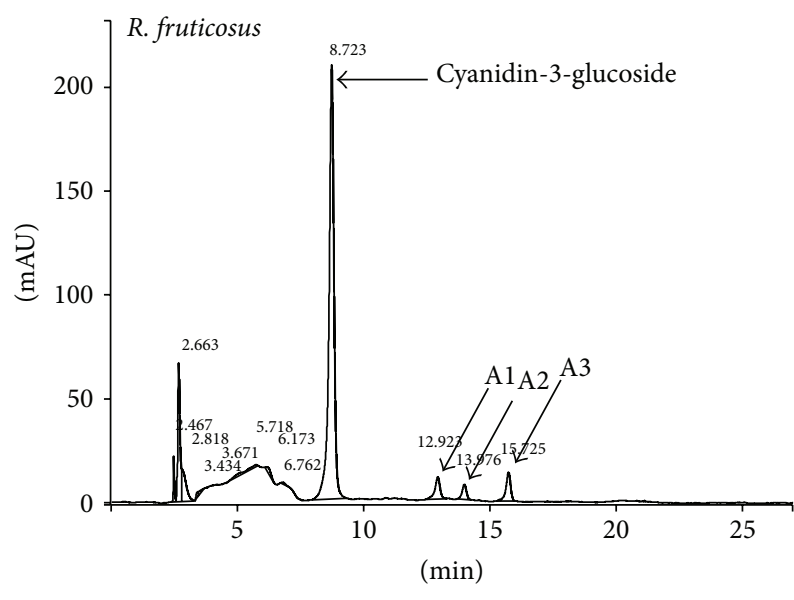

Figure 2: Anthocyanins in blackberry methanolic extract.

3.2. Ellagic Acid Determination. Ellagic acid is a dimeric condensation product of gallic acid. It can exist as a free form, glycoside, or linked as ellagitannins esterified with glucose. Free ellagic acid levels are generally low, although substantial quantities of these compounds can be detected after acid hydrolysis of extracts, as a result of ellagitannin breakdown [8, 21, 31]. For this reason, ellagic acid was generally determined in the free form after acid hydrolysis. Different analytical methods have been previously reported in literature, having some differences in $\mathrm{HCl}$ concentration in the mixture reaction, temperature, and time of reaction. Moreover, the acid hydrolysis was performed directly on the homogenized sample or after a preliminary extraction of the phenolic substances. Generally ellagic acid was determined after an acid hydrolysis over the homogenized berry fruits in a mixture containing a final concentration of $1.2-2 \mathrm{M} \mathrm{HCl}$ and refluxed for 2 to $20 \mathrm{~h}$ at a temperature ranging from 85 to $95^{\circ} \mathrm{C}[7,31-33]$. More recently, Tarola et al. [21] performed an acid hydrolysis over the methanolic extracts obtained from strawberry (final concentration of $4 \mathrm{M} \mathrm{HCl}$ ) for $50 \mathrm{~min}$ in an oven at $90^{\circ} \mathrm{C}$. These acid hydrolysis conditions were demonstrated to be efficient to produce aglycone from ellagic acid compounds, and free ellagic acid was well retained after the acid treatment, whereas other phenolic compounds, such as ferulic acid and catechin, were partially degraded. We compared two analytical methods for acid ellagic determination in blackberry and elderberry fruits. The first was based on the range of conditions more frequently utilized in literature and precisely a simultaneous extraction and hydrolysis of ellagic acid compounds on homogenized fruits under reflux for $5 \mathrm{~h}$ at $90^{\circ} \mathrm{C}$, whereas the second was based on a preliminary extraction of phenolics in an ultrasonic bath and a subsequently rapid acid hydrolysis in a small volume reaction. Confirming what was previously reported in literature, ellagic acid was not detected in elderberry, whereas blackberry was a good source of this bioactive compound (Table 3) $[14,31]$. The results obtained from blackberry fruits showed that the second method increased the recovery of ellagic acid. Moreover, the second method considerably reduced the analysis time and the consumption of solvents.

\section{Conclusions}

The use of ultrasonic-assisted extraction improved the recovery of berry fruit poyphenols in methanolic extract, allowing a rapid extraction procedure, with subsequent reduction in time consuming. The possibility of utilizing microvolume of mixture reaction in acidic hydrolysis in order to obtain free aglycones from glycosides was also suggested, with advantages in solvent cost and disposal.

\section{Conflict of Interests}

The authors declare that there is no conflict of interests regarding the publication of this paper.

\section{Acknowledgments}

The authors thank Professor Simona Fascetti and Dr. Leonardo Rosati for assistance in botanical species identification.

\section{References}

[1] A. Sidor and A. Gramza-Michałowska, "Advanced research on the antioxidant and health benefit of elderberry (Sambucus nigra) in food-a review," Journal of Functional Foods, 2014.

[2] A. M. Inarejos-Garcia, A. Androulaki, M. D. Salvador, G. Fregapane, and M. Z. Tsimidou, "Discussion on the objective 
evaluation of virgin olive oil bitterness," Food Research International, vol. 42, no. 2, pp. 279-284, 2009.

[3] A. S. Dhanani, S. B. Gaudana, and T. Bagchi, "The ability of Lactobacillus adhesin EF-Tu to interfere with pathogen adhesion," European Food Research and Technology, vol. 232, no. 5, pp. 777-785, 2011.

[4] H. Yang, D. Hewes, S. Salaheen, C. Federman, and D. Biswas, "Effects of blackberry juice on growth inhibition of foodborne pathogens and growth promotion of Lactobacillus," Food Control, vol. 37, no. 1, pp. 15-20, 2014.

[5] M. J. Anttonen and R. O. Karjalainen, "Environmental and genetic variation of phenolic compounds in red raspberry," Journal of Food Composition and Analysis, vol. 18, no. 8, pp. 759769, 2005.

[6] S. Y. Wang and H.-S. Lin, "Antioxidant activity in fruits and leaves of blackberry, raspberry, and strawberry varies with cultivar and developmental stage," Journal of Agricultural and Food Chemistry, vol. 48, no. 2, pp. 140-146, 2000.

[7] S. Sellappan, C. C. Akoh, and G. Krewer, "Phenolic compounds and antioxidant capacity of Georgia-grown blueberries and blackberries," Journal of Agricultural and Food Chemistry, vol. 50, no. 8, pp. 2432-2438, 2002.

[8] M. da Silva Pinto, F. M. Lajolo, and M. I. Genovese, "Bioactive compounds and quantification of total ellagic acid in strawberries (Fragaria x ananassa Duch.)," Food Chemistry, vol. 107, no. 4, pp. 1629-1635, 2008.

[9] J. K. Rutz, G. B. Voss, and R. C. Zambiazi, "Influence of the degree of maturation on the bioactivecompounds in backberry (Rubus spp.) cv. Tupy," Food and Nutrition Sciences, vol. 03, no. 10, pp. 1453-1460, 2012.

[10] N. P. Seeram, "Berries," in Nutritional Oncology, D. Heber, G. Blackburn, V. L. W. Go, and J. Milner, Eds., pp. 615-625, Academic Press, London, UK, 2nd edition, 2006.

[11] C. W. I. Haminiuk, G. M. Maciel, M. S. V. Plata-Oviedo, and R. M. Peralta, "Phenolic compounds in fruits-an overview," International Journal of Food Science \& Technology, vol. 47, no. 10, pp. 2023-2044, 2012.

[12] I. Ignat, I. Volf, and V. I. Popa, "A critical review of methods for characterisation of polyphenolic compounds in fruits and vegetables," Food Chemistry, vol. 126, no. 4, pp. 1821-1835, 2011.

[13] S. H. Nile and S. W. Park, "Edible berries: bioactive components and their effect on human health," Nutrition, vol. 30, no. 2, pp. 134-144, 2014.

[14] J. Milivojević, V. Maksimović, M. Nikolić, J. Bogdanović, R. Maletić, and D. Milatović, "Chemical and antioxidant properties of cultivated and wild fragaria and rubus berries," Journal of Food Quality, vol. 34, no. 1, pp. 1-9, 2011.

[15] J. Lee, R. W. Durst, and R. E. Wrolstad, "Determination of total monomeric anthocyanin pigment content of fruit juices, beverages, natural colorants, and wines by the $\mathrm{pH}$ differential method: collaborative study," Journal of AOAC International, vol. 88, no. 5, pp. 1269-1278, 2005.

[16] A. Bunea, D. O. Rugină, A. M. Pintea, Z. Sconţa, C. I. Bunea, and C. Socaciu, "Comparative polyphenolic content and antioxidant activities of some wild and cultivated blueberries from romania," Notulae Botanicae Horti Agrobotanici Cluj-Napoca, vol. 39, no. 2, pp. 70-76, 2011.

[17] R. Veberic, J. Jakopic, F. Stampar, and V. Schmitzer, "European elderberry (Sambucus nigra L.) rich in sugars, organic acids, anthocyanins and selected polyphenols," Food Chemistry, vol. 114, no. 2, pp. 511-515, 2009.
[18] E. González-Molina, A. Gironés-Vilaplana, P. Mena, D. A. Moreno, and C. García-Viguera, "New beverages of lemon juice with elderberry and grape concentrates as a source of bioactive compounds," Journal of Food Science, vol. 77, no. 6, pp. C727C733, 2012.

[19] L. Jakobek and M. Seruga, "Influence of anthocyanins, flavonols and phenolic acids on the antiradical activity of berries and small fruits," International Journal of Food Properties, vol. 15, no. 1, pp. 122-133, 2012.

[20] C. Osorio, N. Hurtado, C. Dawid, T. Hofmann, F. J. HerediaMira, and A. L. Morales, "Chemical characterisation of anthocyanins in tamarillo (Solanum betaceum Cav.) and Andes berry (Rubus glaucus Benth.) fruits," Food Chemistry, vol. 132, no. 4, pp. 1915-1921, 2012.

[21] A. M. Tarola, F. Van de Velde, L. Salvagni, and R. Preti, "Determination of phenolic compounds in strawberries (Fragaria ananassa Duch) by high Performance liquid chromatography with diode array detection," Food Analytical Methods, vol. 6, no. 1, pp. 227-237, 2013.

[22] J. Ivanovic, V. Tadic, S. Dimitrijevic, M. Stamenic, S. Petrovic, and I. Zizovic, "Antioxidant properties of the anthocyanincontaining ultrasonic extract from blackberry cultivar ‘Čačanska Bestrna,' Industrial Crops and Products, vol. 53, pp. 274-281, 2014.

[23] C. E. Tamer, "A research on raspberry and blackberry marmalades produced from different cultivars," Journal of Food Processing and Preservation, vol. 36, no. 1, pp. 74-80, 2012.

[24] S. Pignatti, Flora d'Italia, Edagricole, vol. 1-3, 2011.

[25] Z. Ageel, J. Preston, J. Layne, and S. Baugh, "HPLC-UV Analysis of flavonoids from ginkgo biloba extracts," Notes TN-1140, Phenomenex, 2012.

[26] M. Sójka, S. Guyot, K. Kolodziejczyk, B. Król, and A. Baron, "Composition and properties of purified phenolics preparations obtained from an extract of industrial blackcurrant (Ribes nigrum L.) pomace," Journal of Horticultural Science \& Biotechnology, vol. 84, pp. 100-106, 2009.

[27] J. M. Awika, L. W. Rooney, and R. D. Waniska, "Anthocyanins from black sorghum and their antioxidant properties," Food Chemistry, vol. 90, no. 1-2, pp. 293-301, 2005.

[28] X. Wu, L. Gu, R. L. Prior, and S. McKay, "Characterization of anthocyanins and proanthocyanidins in some cultivars of Ribes, Aronia, and Sambucus and their antioxidant capacity," Journal of Agricultural and Food Chemistry, vol. 52, no. 26, pp. 7846-7856, 2004.

[29] A. Schieber, P. Keller, and R. Carle, "Determination of phenolic acids and flavonoids of apple and pear by high-performance liquid chromatography," Journal of Chromatography A, vol. 910, no. 2, pp. 265-273, 2001.

[30] M. Mandrone, B. Lorenzi, A. Maggio et al., "Polyphenols pattern and correlation with antioxidant activities of berries extracts from four different populations of Sicilian Sambucus nigra L," Natural Product Research, vol. 28, no. 16, pp. 1246-1253, 2014.

[31] L. Jakobek, M. Seruga, I. Novak, and M. Kosanovic, "Flavonols, phenolics acids and antioxidant activity of some red fruit," Deutsche Lebensmittel Rundschau, vol. 103, pp. 369-378, 2007.

[32] R. Nowak, "Determination of ellagic acid in pseudofruits of some species of roses," Acta Poloniae Pharmaceutica-Drug Research, vol. 63, no. 4, pp. 289-292, 2006.

[33] P. Mattila and J. Kumpulainen, "Determination of free and total phenolic acids in plant-derived foods by HPLC with diodearray detection," Journal of Agricultural and Food Chemistry, vol. 50, no. 13, pp. 3660-3667, 2002. 

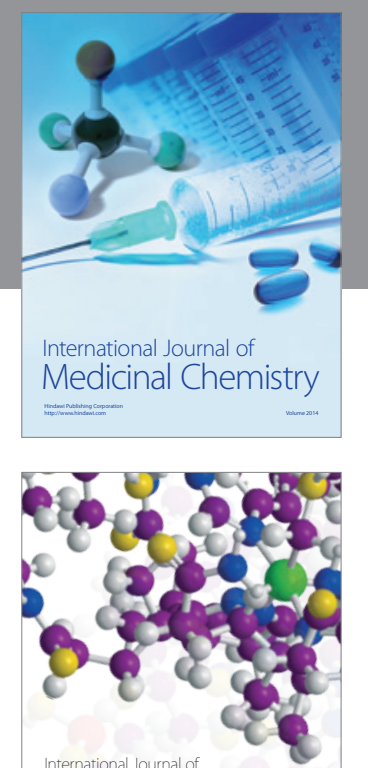

\section{Carbohydrate} Chemistry

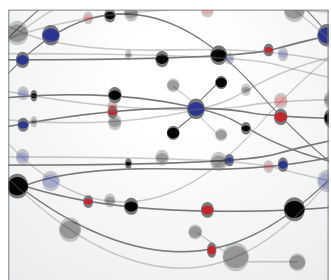

The Scientific World Journal
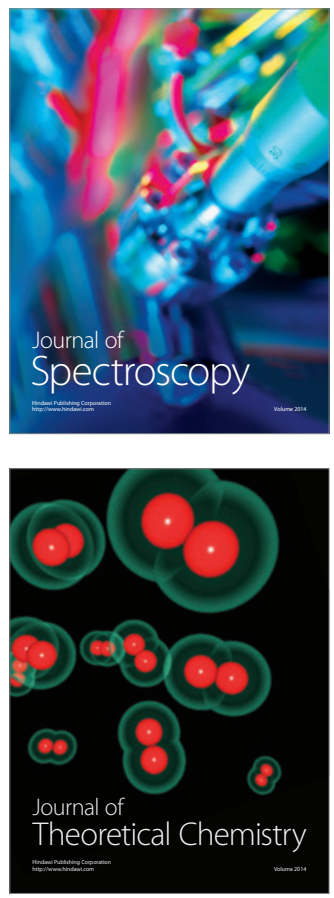
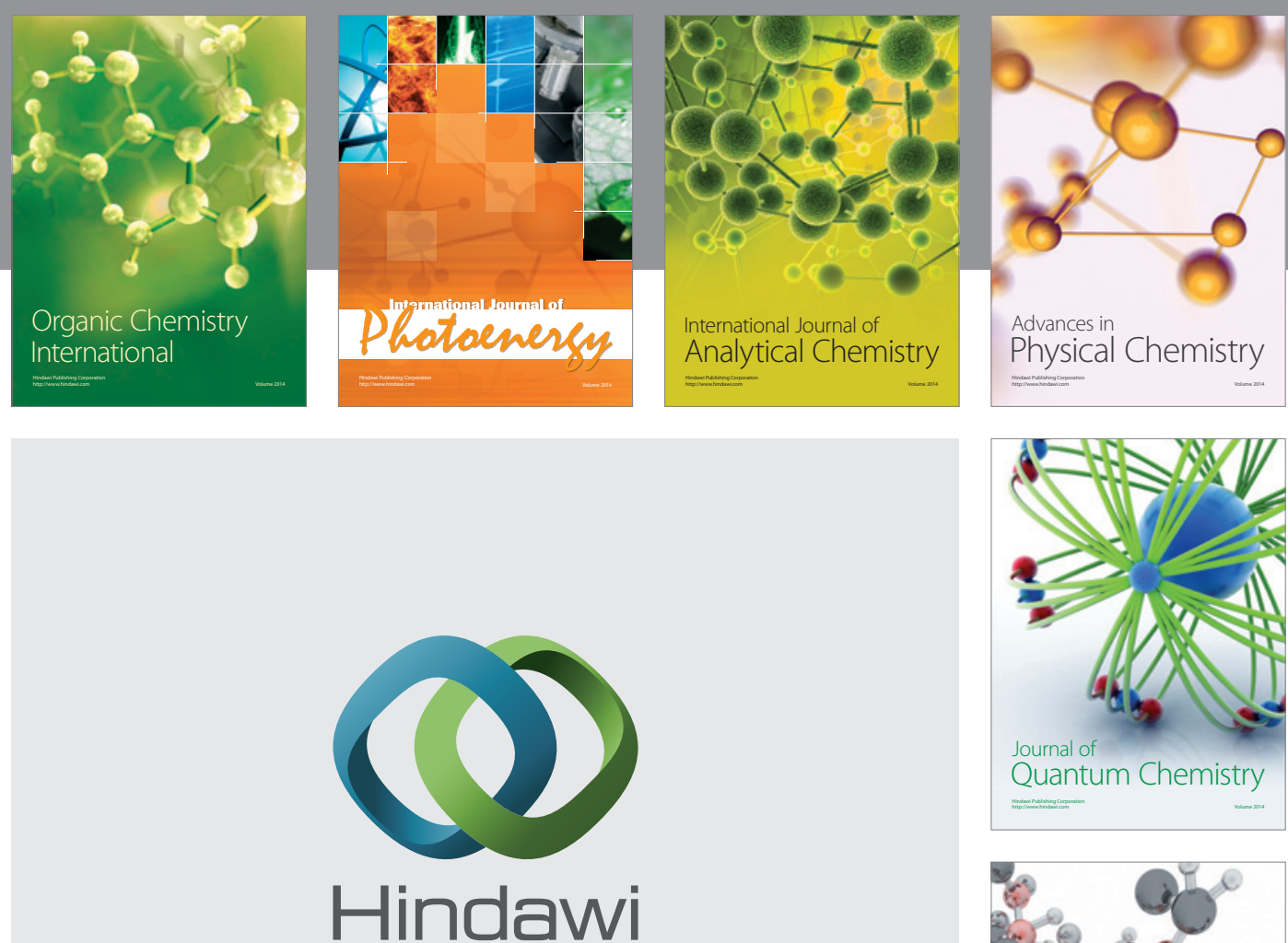

Submit your manuscripts at

http://www.hindawi.com

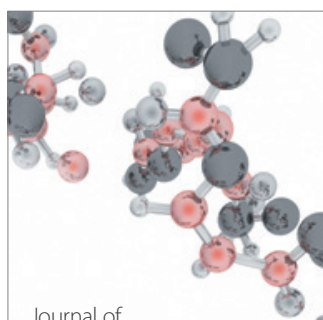

Analytical Methods

in Chemistry

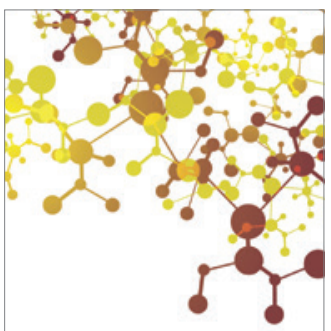

Journal of

Applied Chemistry

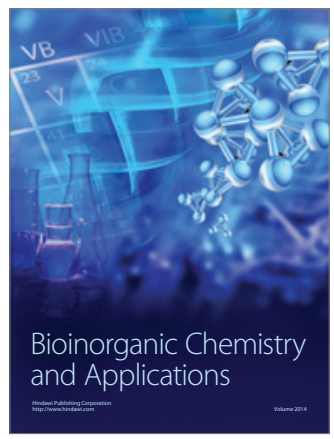

Inorganic Chemistry
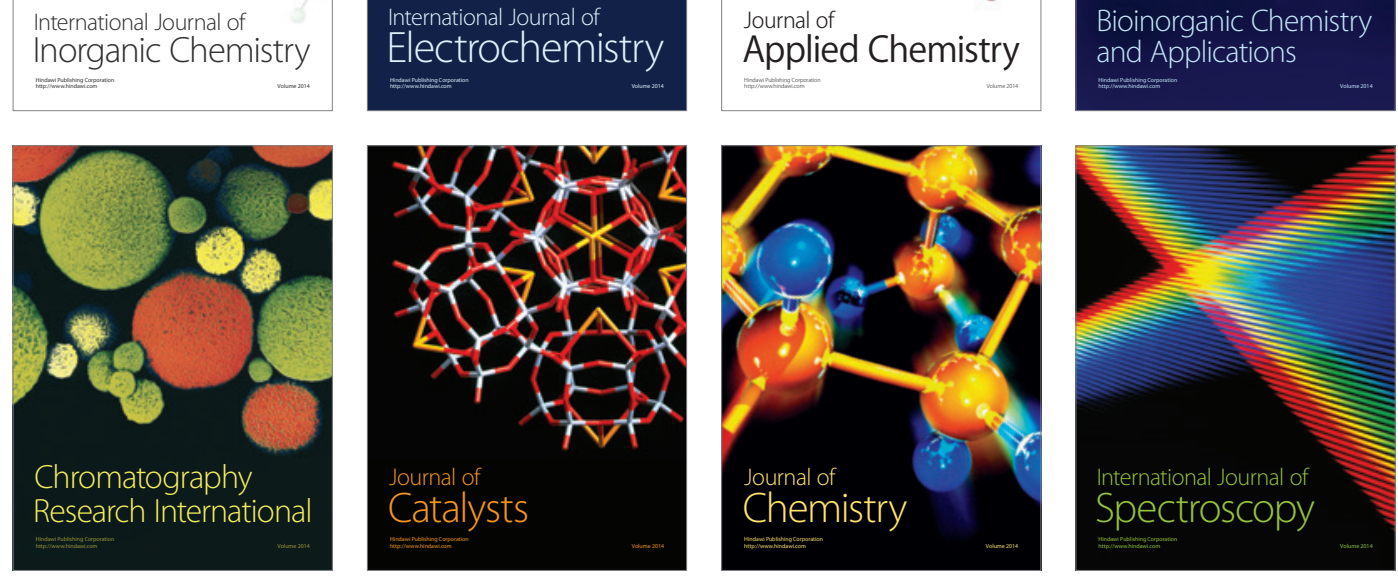